\title{
Abrasion Resistance of Ultra-High-Performance Concrete for Railway Sleepers
}

\author{
Ariful Hasnat $^{1}$ (I) $\cdot$ Nader Ghafoori ${ }^{1}$
}

Received: 26 November 2020/Revised: 9 February 2021 / Accepted: 5 March 2021/Published online: 17 April 2021

(C) The Author(s) 2021

\begin{abstract}
This study aimed to determine the abrasion resistance of ultra-high-performance concretes (UHPCs) for railway sleepers. Test samples were made with different cementitious material combinations and varying steel fiber contents and shapes, using conventional fine aggregate. A total of 25 UHPCs and two high-strength concretes (HSCs) were selected to evaluate their depth of wear and bulk properties. The results of the coefficient of variation $(\mathrm{CV})$, relative gain in abrasion, and abrasion index of the studied UHPCs were also obtained and discussed. Furthermore, a comparison was made on the resistance to wear of the selected UHPCs with those of the HSCs typically used for prestressed concrete sleepers. The outcomes of this study revealed that UHPCs displayed excellent resistance against abrasion, well above that of HSCs. Amongst the utilized cementitious material combinations, UHPCs made with silica fume as a partial replacement of cement performed best against abrasion, whereas mixtures containing fly ash showed the highest depth of wear. The addition of steel fibers had a more positive influence on the abrasion resistance than it did on compressive strength of the studied UHPCs.
\end{abstract}

\footnotetext{
Ariful Hasnat

hasnat@unlv.nevada.edu

Nader Ghafoori

nader.ghafoori@unlv.edu

1 Department of Civil and Environmental Engineering and Construction, University of Nevada, Las Vegas, 4505 Maryland Parkway, Box 454015, Las Vegas 89154-4015 NV, United States
}

Communicated by Baoming Han.
Keywords Abrasion resistance - Railway sleeper - Wear · Ultra-high-performance concrete $\cdot$ High-strength concrete . Cementitious materials $\cdot$ Steel fiber

\section{Introduction}

Presently, timber is the most widely used material in producing railway sleepers. Every year, the USA replaces approximately 14 million timber sleepers [1]. However, timber is susceptible to physical and mechanical degradations that lead to early-age replacements. The scarcity and maintainability of wood as a sleeper material has become a problem over time, and many countries need an alternative material for sleeper production. The new requirements of different codes and standards called for a sleeper element that allows reliable connectivity for the rail, as well as longer service life and higher lateral track stiffness. Moreover, the loading patterns of a new generation of highspeed railway tracks are different from conventional ones. These new types of railway demand additional features from the rail track system in terms of physical, mechanical, and durability aspects, which timber sleepers lack. In this context, prestressed concrete sleepers have become popular for use in high-speed tracks [2].

During the early 1960s, when prestressed concrete was adopted by the railway industry, the service life expectancy of prestressed concrete sleepers was about 50 years, which is 20 years more than that of timber sleepers. However, due to the increase in load, speed, and traffic volumes in railway transport systems, prestressed concrete has failed to perform well in many cases [3-6]. As a point of reference, in 1997, about 120,000 concrete sleepers installed by Amtrak lasted only 4 years before replacements were made [7]. In addition, early deterioration of concrete because of 
cracking, tensile fracture, low flexural stiffness, and substantial self-weight, as well as its low capacity for rail-seat abrasion, has made it challenging for the railway industry to use prestressed concrete as a railway sleeper, especially on high-speed tracks [8].

Over the last three decades, researchers in different parts of the world have been investigating the failures of concrete sleepers and looking for sustainable solutions. Among many factors that affect the mechanical properties and durability of concrete, one of the common reasons for deterioration is abrasion (Fig. 1). Most commonly, concrete pavement, railway concrete sleepers, bridge piers, and industrial floors have been severely affected due to abrasion stresses generated from friction, skidding, sliding, or rubbing [9-11]. According to the American Society for Testing and Materials (ASTM), abrasion is defined as "physical wear due to hard particles or protuberances forced against and moving a solid interface." The American Concrete Institute (ACI) defines abrasion damage as "wearing away of a surface by rubbing and friction" [12]. Per ASTM, abrasion resistance is expressed either in terms of wear index, weight loss, depth of wear, or wear cycles. In prestressed concrete sleepers, failure is caused either by rail-seat abrasion, hydro-abrasive erosion, or hydraulic pressure cracking. Rail-seat abrasion occurs due to the relative movements between the rail pad and concrete rail seat, which subsequently result in the gradual wearing away of the cement paste from the concrete by frictional forces. Several factors are responsible for rail-seat abrasion, including (1) water presence, (2) heavy axle loads, (3) fastener failure, (4) shoulders or sleeper pads, (5) steep track gradients, and (6) track curves greater than two degrees [13, 14].

Resistance to concrete abrasion depends on many factors, including water-to-cementitious materials ratio, compressive strength, aggregate quality, aggregate-paste interface, aggregate fineness, curing, and surface finishing $[15,16]$. Over the years, a number of researches have addressed concrete pavement, sleeper, and bridge deterioration due to surface wear [17-19, 42-47]. Ghafoori and Sukandar [20] stated that the testing condition had more impact on abrasion resistance than the strength of concrete.

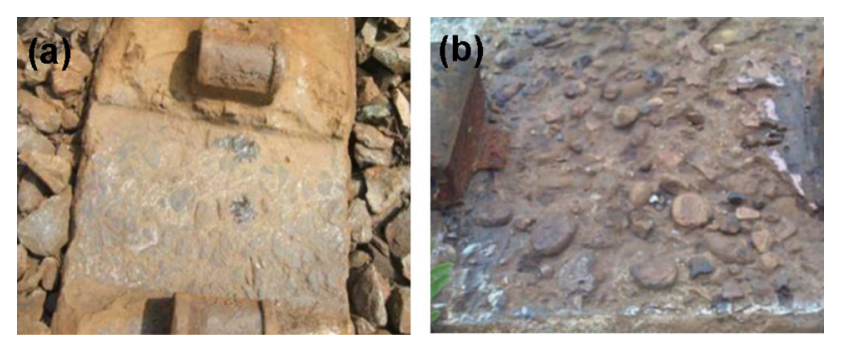

Fig. 1 Prestressed concrete rail-seat abrasion: a Reiff et al. [13], b Zeman et al. [7]
Naik et al. [21] observed that for high-strength concrete, up to $30 \%$ of class $\mathrm{C}$ fly ash replacement gave similar abrasion resistance compared to concrete without fly ash. Additionally, Atis [22] concluded that the presence of fly ash improved the micromorphology of calcium silicate hydrate (C-S-H) gel, which resulted in enhanced cohesion between aggregate and paste, and improvement in abrasion resistance. Further, Siddique [23] replaced fine aggregate with up to $40 \%$ class $\mathrm{F}$ fly ash and found $40 \%$ improvement in abrasion resistance. In another study, Ghafoori and Diawara [24] showed increases in abrasion resistance by incorporating up to $10 \%$ silica fume in the concrete as a partial replacement of fine aggregate. Later, Ghafoori et al. [25] reported that self-compacting concrete performed better than the conventional vibratory-placed concrete in resisting abrasion. They also investigated the effect of the cement content and water-to-cementitious materials ratio, and concluded that an increase of cement content and a decrease of water-to-cementitious materials ratio improved abrasion resistance [25, 26]. Another investigation done by Ghafoori and Dutta [27] showed that a higher aggregatecement ratio reduced resistance to abrasion, and that compaction energy played an important role in resisting concrete wear. In other research, Sadegzadeh et al. [28] studied the influence of various surface finishing techniques on wear resistance, and identified that the near surface porosity of concrete controlled its wear performance. Additionally, Nanni [29] concluded that the moisture condition of concrete's surface had a significant effect on abrasion performance.

Ngamkhanong et al. [42] studied the effect of surface abrasion on the impact capacity of prestressed concrete sleepers. They concluded that surface abrasion reduced the moment capacity of the studied sleepers. Ngamkhanong et al. [43] further concluded that surface abrasion reduced the strength and impact capacity of concrete sleepers. Another study by Li et al. [44] showed that abrasion at the rail seat had less influence on creep and shrinkage than it did on the bottom of a sleeper. Later, You et al. [45] concluded that increases in concrete's tensile strength also increased the cracking load capacity of railway sleepers, whilst ultimate load capacity remained unchanged. Then Kernes et al. [46] improved the abrasion performance of concrete sleepers by grinding off the top mortar paste layer. Although many studies tried to minimize or solve the problem of concrete deterioration caused by abrasion, it still remains a major concern for prestressed concrete sleeper abrasion performance.

According to the Portland Cement Association (PCA) [30], "Ultra-high performance concrete (UHPC) is a concrete material that has a minimum specified compressive strength of $120 \mathrm{MPa}$ with specified durability, tensile ductility, and toughness requirements; fiber are generally 
included in the mixture to achieve specified requirements." Because of the very high production costs, which are about 10 to 20 times higher than the conventional concrete $[31,32]$, only a few proprietary mixtures have been used by different researchers in the assessment of UHPC properties. To compensate for the very high production cost of UHPCs, Karim et al. [33] used masonry sand in place of expensive quartz sand and compared the results with those of the proprietary UHPCs. Further, Arora et al. [34] combined coarse and fine aggregates using a compressible packing model to achieve a compressive strength of 150 MPa. To reduce the total cost, Yang et al. [35] utilized supplementary cementitious material such as fly ash and slag as a partial replacement of cement. Meng et al. [36] employed hybrid fibers and evaluated the fresh and mechanical properties of nonproprietary UHPCs. In another study, Zmetra et al. [37] used UHPC to repair an existing bridge girder and reported that successful restoration of the damaged section. The superior strength and improved longevity potential of UHPC can increase the targeted lifespan of the concrete structure significantly with minimum maintenance costs, thus compensating for its initial production cost.

While there has been growing attention to UHPCs' fresh and mechanical properties, there have been limited published studies on their abrasion resistance (Table 1). In one study, Graybeal and Tanesi [38] used ASTM C 944 to determine the abrasion resistance of UHPCs by measuring the amount of concrete abraded off from the concrete's surface. They found that steam-treated UHPC significantly enhanced the wear resistance, as compared to that of customarily cured samples. However, their testing was limited to only 400 revolutions. Further, Zhao et al. [39] utilized the nano-scratch test, as per BS 812-113, to evaluate wear performance of UHPC, and compared it with high-performance concrete (HPC). They concluded that UHPC showed a 50\% higher abrasion resistance than that of HPC. Additionally, Pyo et al. [40] compared the effect of aggregate type and size on abrasion resistance, and found that the UHPCs made with coarser aggregates produced lower abrasion resistance than the UHPCs batched with finer aggregate sizes.

Amongst the past studies, no investigation has focused on the abrasion resistance of UHPCs for railway sleepers. To this end, the purpose of this study was: (1) to determine the abrasion resistance of selected UHPCs made with different cementitious material combinations, and varying steel fiber contents and shapes; (2) to ascertain the parameters influencing the wear resistance of UHPCs; and (3) to compare the resistance to wear of the studied UHPCs with those of the high-strength concrete (HSC) typically used in the production of railway sleepers.

\section{Experimental Program}

\subsection{Materials}

In the production of the UHPC mixtures, ASTM Type V Portland cement, class F fly ash, and silica fume were used as cementitious materials. The chemical characteristics of the cementitious materials are presented in Table 2. Two

Table 1 Studies on UHPC abrasion

\begin{tabular}{|c|c|c|c|c|c|c|c|}
\hline Ref. & Variations & Binder composition $^{\mathrm{c}}$ & Test details & $\begin{array}{l}\text { No. of } \\
\text { revolution }\end{array}$ & $\begin{array}{l}f^{\prime} c \\
(\mathrm{MPa})\end{array}$ & $\begin{array}{l}\text { Depth of } \\
\text { abrasion } \\
(\mathrm{mm})\end{array}$ & $\begin{array}{l}\text { Mass } \\
\text { loss }(g)\end{array}$ \\
\hline \multirow[t]{4}{*}{ Pyo et al. [40] } & $\mathrm{SN} 1.5^{\mathrm{a}}$ & \multirow{4}{*}{$\begin{array}{l}1 \mathrm{C}^{\mathrm{d}}, 0.05-0.25 \mathrm{SF}^{\mathrm{d}} ; 0-1.5 \% \text { steel } \\
\quad \text { fiber }^{\mathrm{d}} ; \mathrm{w} / \mathrm{cm}=0.22-0.30\end{array}$} & \multirow{4}{*}{$\begin{array}{l}\text { ASTM C944: Load } \\
\quad 44 \mathrm{lb}, 200 \mathrm{rpm}^{\mathrm{f}}\end{array}$} & \multirow[t]{4}{*}{16000} & 161 & 0.23 & 2.5 \\
\hline & $\mathrm{SD} 1.5^{\mathrm{a}}$ & & & & 151 & 0.39 & 4.05 \\
\hline & $\mathrm{SB} 1.5^{\mathrm{a}}$ & & & & 130 & 0.43 & 4.87 \\
\hline & $\mathrm{HSC}$ & & & & 67.8 & 2 & $2^{\mathrm{g}}$ \\
\hline \multirow[t]{2}{*}{ Zhao et al. [39] } & UHPC & $415-520 \mathrm{C}^{\mathrm{e}}, 0-160 \mathrm{~F}^{\mathrm{e}}, 0-120 \mathrm{SF}^{\mathrm{e}}$ & \multirow{2}{*}{$\begin{array}{l}\text { BS 812-113: Load } \\
\quad 4.4 \mathrm{lb}, 60 \mathrm{rpm}^{\mathrm{f}}\end{array}$} & \multirow[t]{2}{*}{6000} & - & 1.9 & - \\
\hline & $\mathrm{HPC}^{\mathrm{b}}$ & $0-1 \%$ steel fiber ${ }^{\mathrm{d}} ; \mathrm{w} / \mathrm{cm}=0.20$ & & & - & 3.1 & - \\
\hline $\begin{array}{l}\text { Graybeal and } \\
\text { Tanesi [38] }\end{array}$ & UHPC & $\begin{array}{l}712 \mathrm{C}^{\mathrm{e}}, 231 \mathrm{SF}^{\mathrm{e}} ; 2 \% \text { steel fiber } \\
\text { w/cm }\end{array}$ & $\begin{array}{l}\text { ASTM C944: Load } \\
\qquad 44 \mathrm{lb}, 200 \mathrm{rpm}^{\mathrm{f}}\end{array}$ & 400 & - & - & 1 \\
\hline \multirow{2}{*}{\multicolumn{8}{|c|}{$\begin{array}{l}\text { a SN: river sand (no coarse aggregate), SD: dolomite and river sand, SB: basalt and river sand; } \\
\text { b } \mathrm{HPC} \text { : high-performance concrete; }\end{array}$}} \\
\hline & & & & & & & \\
\hline \multirow{2}{*}{\multicolumn{8}{|c|}{$\begin{array}{l}{ }^{c} \mathrm{C}: \text { cement, } \mathrm{SF}: \text { silica fume, } \\
{ }^{\mathrm{d}} \text { volume fraction }\end{array}$}} \\
\hline & & & & & & & \\
\hline \multicolumn{8}{|c|}{ e weight $\left(\mathrm{kg} / \mathrm{m}^{3}\right.$ of concrete $)$; } \\
\hline \multicolumn{8}{|c|}{ f rpm: revolutions per minute; } \\
\hline \multicolumn{8}{|c|}{$\mathrm{g}$ at 4000 revolution } \\
\hline
\end{tabular}


Table 2 Chemical compositions of UHPC and HSC cementitious materials (percentage mass)

\begin{tabular}{llll}
\hline Composition & Type V cement $(\%)$ & Class F fly ash (\%) & Silica fume (\%) \\
\hline $\mathrm{SiO}_{2}$ & 21 & 59.93 & 94.72 \\
$\mathrm{CaO}$ & 62.4 & 4.67 & - \\
$\mathrm{Al}_{2} \mathrm{O}_{3}$ & 4 & 22.22 & - \\
$\mathrm{Fe}_{2} \mathrm{O}_{3}$ & 3.7 & 5.16 & - \\
$\mathrm{MgO}$ & 2.6 & - & - \\
$\mathrm{SO}_{3}$ & 2.2 & 0.38 & 0.23 \\
$\mathrm{Na}_{2} \mathrm{O}+\mathrm{K}_{2} \mathrm{O}$ & 0.54 & 1.29 & 0.47 \\
Loss on ignition (LOI) & 2.0 & 0.32 & 2.82 \\
\hline
\end{tabular}

types of locally produced fine aggregates were used. Their size gradation varied from $0.075 \mathrm{~mm}$ to $4.75 \mathrm{~mm}$. To achieve the maximum packing density with the minimum porosity, a uniquely size-graded manufactured fine aggregate was determined. To this end, the relative density was measured for the graded aggregates at different distribution moduli (0.20-0.25), using the modified Andreasen and Andersen model. Maximum packing density was obtained from the distribution modulus of 0.21 . The gradation of the fine aggregate is given in Table 3. The combined fine aggregates had specific gravity of 2.80 and water absorption of $0.45 \%$.

To observe the effects of fiber shape, two types of lowcarbon steel fiber (straight and hooked), with the aspect ratio of 43 , were incorporated into the total volume of concrete. A commercially available polycarboxylate-based high-range water-reducing admixture (HRWRA) was used to achieve the desired flowability of the studied UHPCs. To produce HSCs, ASTM Type V Portland cement and locally available fine and coarse aggregates were used. The fine aggregate had specific gravity of 2.78 and water absorption of $0.81 \%$, whereas the coarse aggregate had specific gravity of 2.76 and water absorption of $0.82 \%$. Both fine and coarse aggregate complied with the ASTM C33 gradation requirements.

Table 3 Aggregate gradation of UHPCs as per the modified Andreasen and Andersen model

\begin{tabular}{lll}
\hline Sieve no. & Sieve opening $(\mathrm{mm})$ & Percentage retained \\
\hline$\# 8$ & 2.38 & 23.5 \\
$\# 16$ & 1.19 & 20.1 \\
$\# 30$ & 0.595 & 17.0 \\
$\# 50$ & 0.297 & 15.1 \\
$\# 100$ & 0.149 & 13.0 \\
$\# 200$ & 0.074 & 11.3 \\
\hline
\end{tabular}

\subsection{Mixture Proportions of UHPCs and HSCs}

A total of 25 UHPCs and two HSCs were used to determine their abrasion resistance through depth of wear. The unit content of the mixture constituents of the selected UHPCs and HSCs is given in Table 4. To observe the effect of secondary cementitious materials, cement was replaced with 20 and $30 \%$ class $\mathrm{F}$ fly ash, 5\% silica fume, and combined $15 \%$ fly ash and $5 \%$ silica fume, in addition to the control UHPC (100\% cement). The water-to-cementitious materials ratio $(\mathrm{w} / \mathrm{cm})$ of 0.21 remained constant for all UHPCs. The actual water content of the UHPCs varied because of the variation in the HRWRA dosage percentage. The dosage of HRWRA varied from 10.1 to $14.3 \mathrm{~kg} / \mathrm{m}^{3}$ depending on the cementitious material combination and the percentage of steel fiber used. The UHPCs with steel fiber and silica fume required higher amounts of HRWRA in order to maintain the desired flowability. Two types of steel fibers, hooked and straight, were used at the levels of 2 and $3 \%$ of the total volume of concrete.

For the studied high-strength concretes (HSCs), representing the typical concretes used in prestressed railway sleepers, two cement contents of 445 and $564 \mathrm{~kg} / \mathrm{m}^{3}$, HSC1 and HSC2, respectively, were used. The water-to-cementitious materials ratio $(\mathrm{w} / \mathrm{cm})$ was kept constant at 0.275 . To accelerate the hydration process of HSCs, a $2 \%$ nonchloride accelerating admixture was used, in addition to the HRWRA. A constant workability of $125 \pm 25 \mathrm{~mm}$ was maintained for the studied HSCs.

\subsection{Mixing, Sampling, Curing, and Testing}

Due to the high quantity of small-sized particles, coupled with the low water-to-cementitious materials ratio and addition of steel fibers, a longer mixing time and higher energy were required for the production of UHPCs, as compared to traditional concrete. The mixing time, mixing speed, mixing sequence, temperature, and relative humidity were closely monitored and uniformly maintained. In this study, the UHPCs' dry cementitious materials were first mixed for $5 \mathrm{~min}$ in a Hobart-type mixing machine. To 
Table 4 Mixture proportion of UHPCs and HSCs

\begin{tabular}{|c|c|c|c|c|c|c|c|c|c|c|c|}
\hline Mixture designation $^{\mathrm{a}}$ & $\begin{array}{l}\mathrm{C}^{\mathrm{b}} \\
\mathrm{kg} / \mathrm{m}^{3}\end{array}$ & $\mathrm{~F}^{\mathrm{b}}$ & $\mathrm{SF}^{\mathrm{b}}$ & $\mathrm{FA}^{\mathrm{b}}$ & $\mathrm{CA}^{\mathrm{b}}$ & HRWRA $^{\mathrm{b}}$ & $\mathrm{w} / \mathrm{cm}$ & $\mathrm{W}^{\mathrm{b}}$ & Steel fibers & Flow $(\mathrm{mm})$ & Unit weight $\left(\mathrm{kg} / \mathrm{m}^{3}\right)$ \\
\hline C100 & 1101 & - & - & 1174 & - & 12.1 & 0.21 & 226 & - & 248 & 2470 \\
\hline $\mathrm{C} 100-\mathrm{H} 2 \%$ & 1101 & - & - & 1174 & - & 13.2 & 0.21 & 226 & 156 & 241 & 2536 \\
\hline $\mathrm{C} 100-\mathrm{S} 2 \%$ & 1101 & - & - & 1174 & - & 13.2 & 0.21 & 226 & 156 & 256 & 2531 \\
\hline $\mathrm{C} 100-\mathrm{H} 3 \%$ & 1101 & - & - & 1174 & - & 14.3 & 0.21 & 225 & 234 & 251 & 2585 \\
\hline $\mathrm{C} 100-\mathrm{S} 3 \%$ & 1101 & - & - & 1174 & - & 14.3 & 0.21 & 225 & 234 & 271 & 2592 \\
\hline SF5 & 1046 & - & 39 & 1174 & - & 12 & 0.21 & 215 & - & 273 & 2451 \\
\hline $\mathrm{SF} 5-\mathrm{H} 2 \%$ & 1046 & - & 39 & 1174 & - & 13.1 & 0.21 & 214 & 156 & 247 & 2512 \\
\hline SF5-S2\% & 1046 & - & 39 & 1174 & - & 13.1 & 0.21 & 214 & 156 & 240 & 2506 \\
\hline SF5-H3\% & 1046 & - & 39 & 1174 & - & 14.1 & 0.21 & 214 & 234 & 255 & 2551 \\
\hline SF5-S3\% & 1046 & - & 39 & 1174 & - & 14.1 & 0.21 & 214 & 234 & 250 & 2583 \\
\hline F20 & 881 & 163 & - & 1174 & - & 11 & 0.21 & 215 & - & 270 & 2405 \\
\hline $\mathrm{F} 20-\mathrm{H} 2 \%$ & 881 & 163 & - & 1174 & - & 12 & 0.21 & 215 & 156 & 271 & 2475 \\
\hline $\mathrm{F} 20-\mathrm{S} 2 \%$ & 881 & 163 & - & 1174 & - & 12 & 0.21 & 215 & 156 & 247 & 2491 \\
\hline F20-H3\% & 881 & 163 & - & 1174 & - & 13 & 0.21 & 214 & 234 & 240 & 2540 \\
\hline F20-S3\% & 881 & 163 & - & 1174 & - & 13 & 0.21 & 214 & 234 & 255 & 2543 \\
\hline F30 & 771 & 244 & - & 1174 & - & 10.1 & 0.21 & 210 & - & 250 & 2374 \\
\hline $\mathrm{F} 30-\mathrm{H} 2 \%$ & 771 & 244 & - & 1174 & - & 11.2 & 0.21 & 209 & 156 & 269 & 2440 \\
\hline $\mathrm{F} 30-\mathrm{S} 2 \%$ & 771 & 244 & - & 1174 & - & 11.2 & 0.21 & 209 & 156 & 270 & 2446 \\
\hline F30-H3\% & 771 & 244 & - & 1174 & - & 12.2 & 0.21 & 208 & 234 & 246 & 2498 \\
\hline F30-S3\% & 771 & 244 & - & 1174 & - & 12.2 & 0.21 & 208 & 234 & 238 & 2506 \\
\hline F15SF5 & 881 & 122 & 39 & 1174 & - & 11.5 & 0.21 & 214 & - & 253 & 2388 \\
\hline F15SF5-H2\% & 881 & 122 & 39 & 1174 & - & 12.5 & 0.21 & 214 & 156 & 248 & 2483 \\
\hline F15SF5-S2\% & 881 & 122 & 39 & 1174 & - & 12.5 & 0.21 & 214 & 156 & 264 & 2490 \\
\hline F15SF5-H3\% & 881 & 122 & 39 & 1174 & - & 13.5 & 0.21 & 213 & 234 & 265 & 2535 \\
\hline F15SF5-S3\% & 881 & 122 & 39 & 1174 & - & 13.5 & 0.21 & 213 & 234 & 243 & 2535 \\
\hline HSC1 & 386 & - & - & 933 & 1040 & 3.2 & 0.275 & 103 & - & - & - \\
\hline HSC2 & 504 & - & - & 846 & 1034 & 2.5 & 0.275 & 136 & - & - & - \\
\hline
\end{tabular}

$1 \mathrm{~kg} / \mathrm{m}^{3}=1.685 \mathrm{lb} / \mathrm{yd}^{3}$

${ }^{\text {a }}$ C100: $100 \%$ cement, SF5: $95 \%$ cement and 5\% silica fume, F20: $80 \%$ cement and 20\% class F fly ash, F30: $70 \%$ cement and $30 \%$ class F fly ash, F15SF5: $80 \%$ cement and 15\% class F fly ash and 5\% silica fume, S2\% and S3\% represent 2\% and 3\% straight steel fibers, $\mathrm{H} 2 \%$ and $\mathrm{H} 3 \%$ represents $2 \%$ and $3 \%$ hooked steel fibers.

${ }^{\mathrm{b}}$ C: cement; F: class F fly ash, SF: silica fume, HRWRA: high-range water-reducing admixture, CA: coarse aggregate, FA: fine aggregate, W: actual water

reduce agglomeration of particles, fine aggregates were slowly added, and the combined materials were dry-mixed for another 5 min. Afterwards, nearly $90 \%$ of the mixing water was added and mixed for a period of $5 \mathrm{~min}$ before the remainder of water and HRWRA were added. Finally, steel fibers were slowly introduced to the matrix, and mixing continued for additional 3-5 min until a well-dispersed mixture was attained. The flow properties of the studied UHPCs were evaluated according to ASTM C230 (as all the UHPCs were self-compacting, 25 drops of blow were skipped) before they were poured into cylinders $(50-\mathrm{mm}$ diameter and 100 -mm height $)$ and cubes $(300 \times 300 \times 300$ $\mathrm{mm})$. The specimens were kept for $24 \mathrm{~h}$ in a controlled, moist curing room at $22 \pm 3^{\circ} \mathrm{C}$ and $95 \%$ relative humidity. After $24 \mathrm{~h}$, specimens were demolded and returned to the moisture room for an additional 27 days.

A pan-style counter-current mixer was used to batch the studied HSCs. After pouring freshly mixed concrete into the molds, specimens were densified using a vibrating table. The curing method and duration used for the HSCs were similar to those of the UHPCs.

The 28-day-cured UHPCs and HSCs were tested for compressive strength, splitting-tensile resistance, and abrasion resistance as per ASTM C39, ASTM C496, and 
ASTM C779 (procedure C, ball bearings), respectively. The UHPCs' elastic modulus was measured as per ASTM C469. The adopted abrasion test was used to simulate high contact stresses, impact, and sliding friction. This method simulates traffic wear and extreme weather conditions, thus making it suitable for UHPC applications. Moreover, AREMA recommends that the ASTM C779 procedure C should be used to ascertain the abrasion performance of railway sleepers [41]. The abrasion test setup is shown in Fig. 2. The apparatus consisted of 12 equally spaced 18 -mm diameter steel balls inside a bearing plate. A continuous water flow was maintained during testing to remove abraded particles. The depth of abrasion was measured using a dial gauge that could read to the nearest $0.025 \mathrm{~mm}$. The abrasion resistance was evaluated every 30 $\mathrm{s}$ for $20 \mathrm{~min}$ of testing or until a 3.0-mm depth of wear was reached.

\section{Results and Discussion}

\subsection{Fresh and Bulk Properties of UHPCs and HSCs}

The characteristics of the UHPCs' fresh properties are summarized in Table 4. The mini-slump flow was measured immediately upon completion of mixing. A satisfactory flow spread diameter of $250 \pm 25 \mathrm{~mm}$ was attained for all studied UHPCs. As can be seen in Table 4, the demolded unit weight of the UHPCs varied from 2374 to $2592 \mathrm{~kg} / \mathrm{m}^{3}$. The presence of steel fiber increased the unit weight of the studied UHPCs.

The compressive strengths of the studied UHPCs and HSCs are presented in Fig. 3. The 28-day-cured silica fume containing UHPCs provided a slightly better compressive strength than the 28-day-cured fly ash containing mixtures due to their higher reactivity during that curing period.

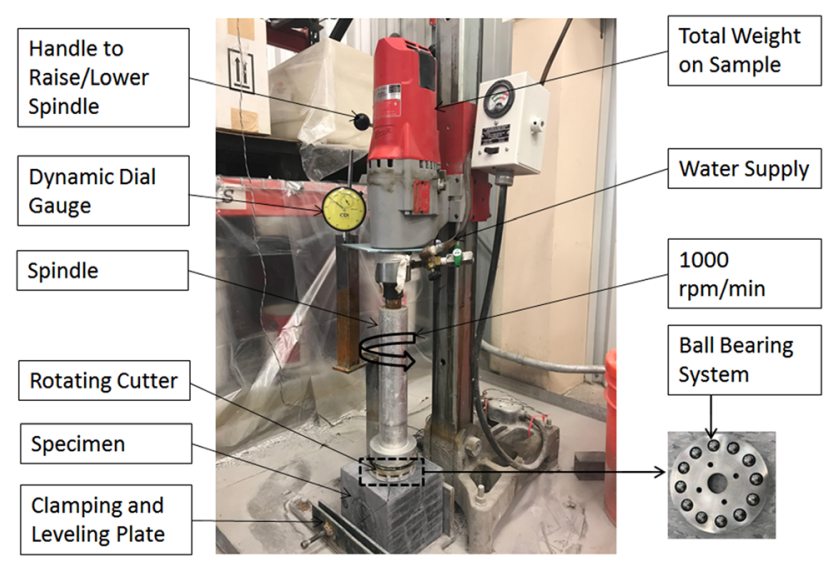

Fig. 2 Abrasion test setup in accordance with ASTM C779, procedure $\mathrm{C}$, ball bearings
Overall, the compressive strength of UHPCs improved marginally with the introduction of steel fiber, with a similar result for both straight and hooked fibers. The mixtures with $2 \%$ hooked or straight fibers experienced a small increase of 2 to $8 \%$ in compressive strength, in comparison with the companion plain UHPCs. A slightly higher increment (4-13\%) was found for the mixtures with $3 \%$ steel fibers. The minor improvement in compressive strength may be attributed to the enhanced micro-crack arrest when fibers were used. As can be seen in Fig. 3, an increase in cement content from 386 to $504 \mathrm{~kg} / \mathrm{m}^{3}$ resulted in a nearly $10 \%$ improvement in the compressive strength of the studied HSCs. When compared to the plain UHPC (C100), HSC1 and HSC2 produced 33 and $26 \%$ lower compressive strengths, respectively.

Figure 4 shows the 28-day splitting-tensile strength of the studied plain and fiber-reinforced UHPCs using different cementitious material combinations. The average splitting-tensile strength of the studied UHPCs varied from 8.8 to $13.1 \mathrm{MPa}$. The UHPCs containing silica fume as a partial replacement of cement performed best amongst the studied mixtures. The incorporation of steel fibers significantly improved the splitting-tensile strength of the studied UHPCs. The addition of $2 \%$ hooked steel fiber resulted in a $17 \%$ improvement in splitting-tensile strength, as compared to that of the companion plain UHPC. With the introduction of $3 \%$ hooked fiber, the corresponding gain in the average splitting-tensile strength was nearly $37 \%$. In comparison, test specimens having 2 and 3\% straight fibers increased their average splitting-tensile strengths by 18 and $38 \%$, respectively. This can be attributed to the anticipated increase in the matrix stiffness of the fiber-reinforced UHPCs. Additionally, steel fibers managed to distribute localized stress to the surrounding concrete and acted as a crack arrester.

As presented in Fig. 4, HSCs show, on average, 42\% lower splitting-tensile strength as compared to that of the plain UHPC (C100). This can be attributed to a lower cementitious material content and higher water-to-cementitious materials ratio, as well as the presence of coarse aggregates, along with variation of the physical properties of the coarse and fine aggregates of the studied HSCs. Once steel fibers were added, the fiber-reinforced UHPC (C100) produced an average $54 \%$ higher splitting-tensile resistance than that of the studied HSCs.

Figure 5 represents the 28-day elastic moduli of the UHPCs. As can be seen, fibers had minimal effects on the elastic moduli of the studied UHPCs. When comparing fiber-reinforced UHPCs to plain UHPCs, the inclusion of 2 and $3 \%$ hooked steel fibers resulted in average elastic moduli increases of 3 and $6 \%$, respectively. In comparison, the improvements in the elastic moduli of the UHPCs made with 2 and $3 \%$ straight steel fibers were 4 and $8 \%$, 
Fig. 3 Compressive strength of the studied UHPCs and HSCs

Fig. 4 Splitting-tensile strength of the studied UHPCs and HSCs

Fig. 5 Elastic modulus of the studied UHPCs and HSCs
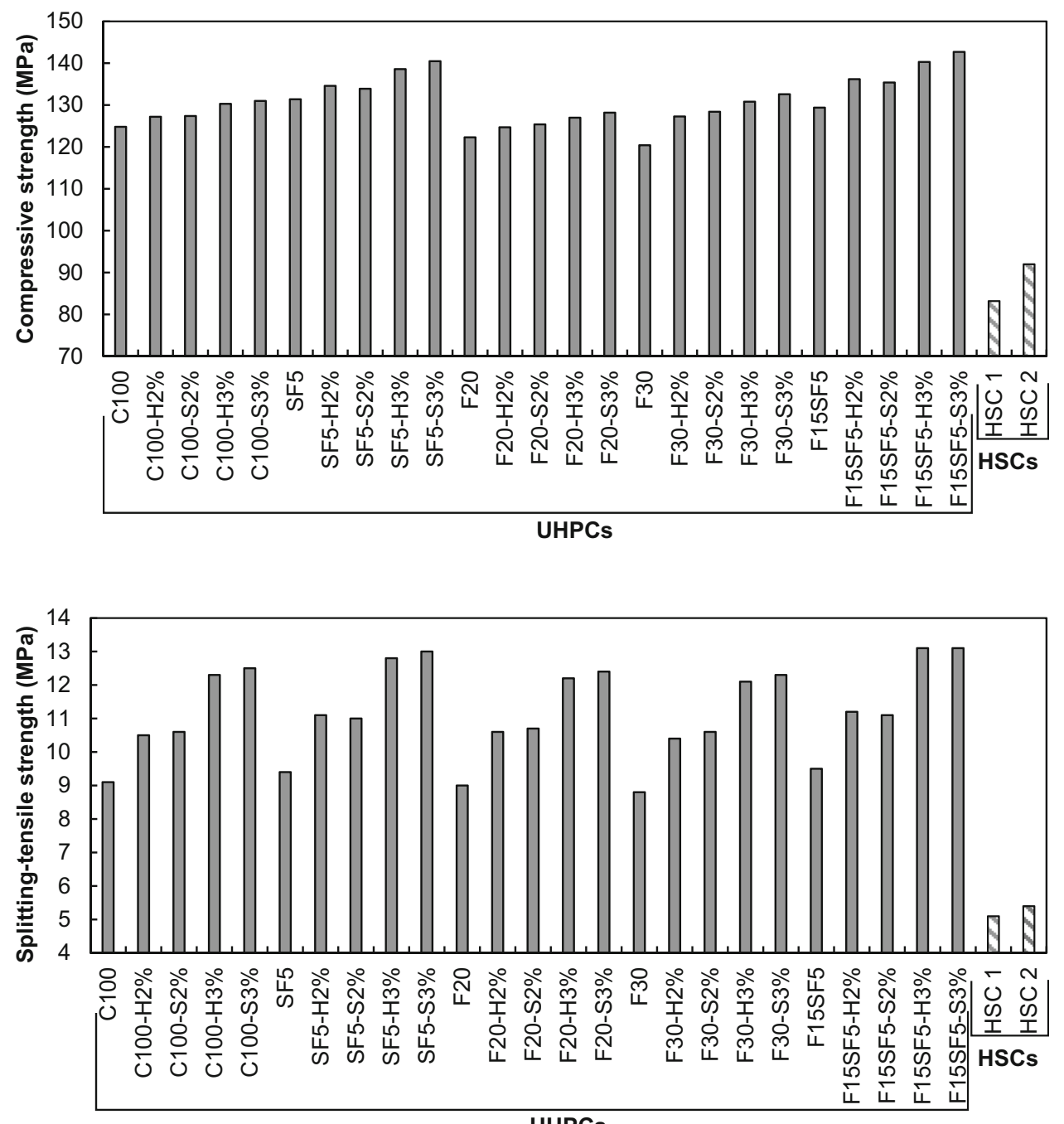

UHPCs

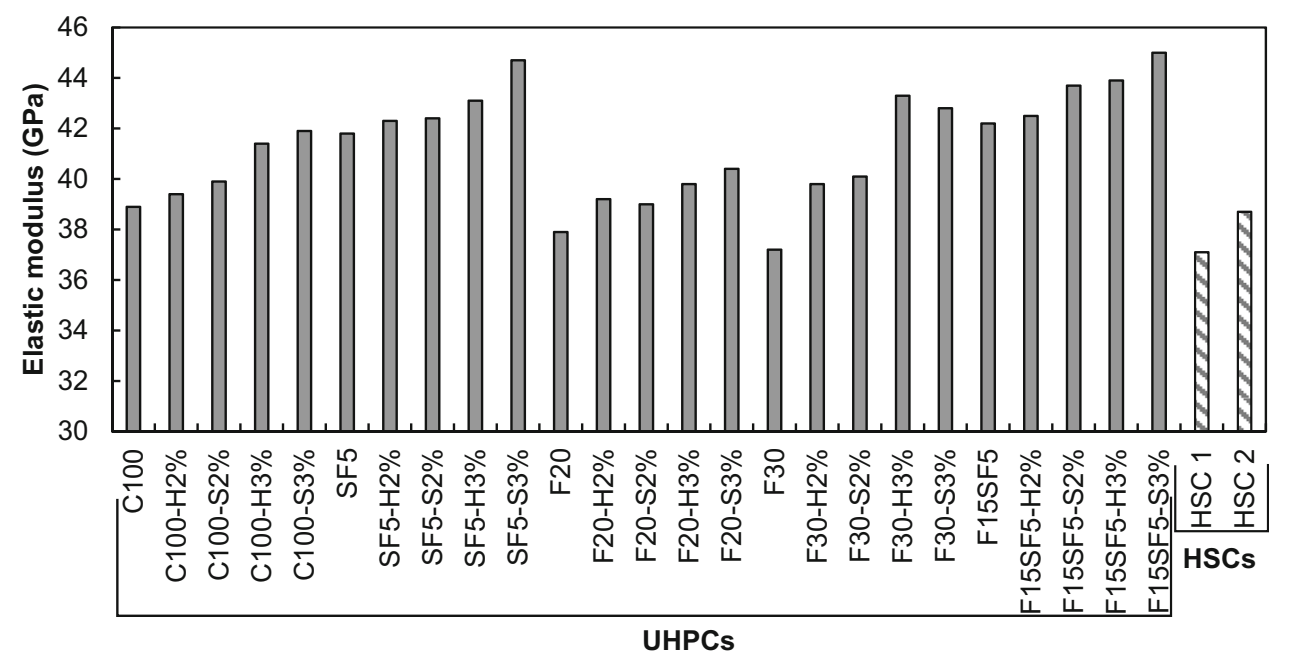


respectively. As can be seen in Fig. 5, the elastic moduli of the studied HSCs were found to be nearly $3 \%$ lower than the plain UHPC (C100).

\subsection{Resistance to Wear of UHPCs}

The results of abrasion depth for the studied UHPCs, as varied by cementitious material combinations and steel fiber content and type, at different time intervals are presented in Table 5. The ultimate depth of abrasion varied from 0.43 to $0.65 \mathrm{~mm}$, reflecting the high surface quality of the studied UHPCs. The influence of cementitious material combinations, steel fiber content, and steel fiber shape on the resistance to wear of the studied UHPCs are discussed in the sections to follow. Additionally, the results of coefficient of variation $(\mathrm{CV})$ and relative gain in abrasion along with the abrasion index $(A I)$ and concrete surface conditions after the abrasion tests of the studied UHPCs are presented and discussed.

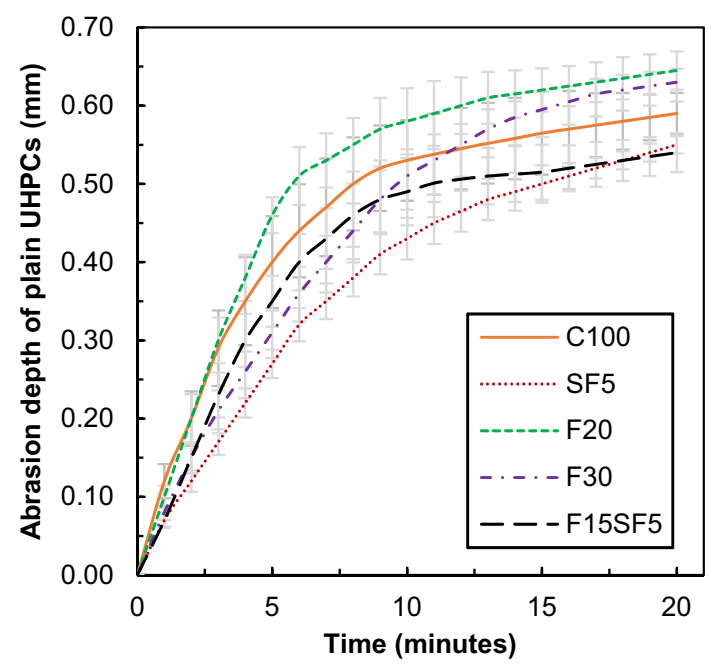

Fig. 6 Depth of wear of plain UHPCs as a function of time
Table 5 Depth of wear at different time intervals

\begin{tabular}{|c|c|c|c|c|c|c|}
\hline \multirow[t]{2}{*}{ Mixture designation } & \multicolumn{6}{|c|}{ Depth of wear at various time intervals (mm) } \\
\hline & $1 \mathrm{~min}$ & $2 \mathrm{~min}$ & $5 \min$ & $10 \mathrm{~min}$ & $15 \min$ & $20 \min$ \\
\hline $\mathrm{C} 100$ & 0.12 & 0.20 & 0.40 & 0.53 & 0.57 & 0.59 \\
\hline $\mathrm{C} 100-\mathrm{H} 2 \%$ & 0.10 & 0.19 & 0.32 & 0.46 & 0.49 & 0.51 \\
\hline C100-S2\% & 0.10 & 0.18 & 0.30 & 0.42 & 0.46 & 0.49 \\
\hline $\mathrm{C} 100-\mathrm{H} 3 \%$ & 0.09 & 0.16 & 0.29 & 0.40 & 0.44 & 0.45 \\
\hline $\mathrm{C} 100-\mathrm{S} 3 \%$ & 0.09 & 0.15 & 0.28 & 0.40 & 0.43 & 0.45 \\
\hline SF5 & 0.07 & 0.12 & 0.27 & 0.43 & 0.50 & 0.55 \\
\hline SF5-H2\% & 0.07 & 0.11 & 0.26 & 0.38 & 0.43 & 0.48 \\
\hline SF5-S2\% & 0.06 & 0.09 & 0.24 & 0.37 & 0.43 & 0.48 \\
\hline SF5-H3\% & 0.05 & 0.09 & 0.23 & 0.35 & 0.41 & 0.43 \\
\hline SF5-S3\% & 0.04 & 0.08 & 0.22 & 0.35 & 0.40 & 0.43 \\
\hline F20 & 0.10 & 0.20 & 0.46 & 0.58 & 0.62 & 0.65 \\
\hline $\mathrm{F} 20-\mathrm{H} 2 \%$ & 0.07 & 0.15 & 0.35 & 0.49 & 0.52 & 0.54 \\
\hline $\mathrm{F} 20-\mathrm{S} 2 \%$ & 0.07 & 0.15 & 0.34 & 0.46 & 0.50 & 0.52 \\
\hline F20-H3\% & 0.06 & 0.11 & 0.27 & 0.39 & 0.44 & 0.46 \\
\hline F20-S3\% & 0.06 & 0.12 & 0.28 & 0.38 & 0.43 & 0.46 \\
\hline F30 & 0.08 & 0.15 & 0.31 & 0.51 & 0.60 & 0.63 \\
\hline $\mathrm{F} 30-\mathrm{H} 2 \%$ & 0.08 & 0.13 & 0.29 & 0.43 & 0.48 & 0.53 \\
\hline $\mathrm{F} 30-\mathrm{S} 2 \%$ & 0.06 & 0.11 & 0.26 & 0.39 & 0.46 & 0.51 \\
\hline F30-H3\% & 0.05 & 0.10 & 0.24 & 0.36 & 0.41 & 0.45 \\
\hline F30-S3\% & 0.05 & 0.09 & 0.23 & 0.34 & 0.40 & 0.45 \\
\hline F15SF5 & 0.07 & 0.15 & 0.35 & 0.49 & 0.52 & 0.54 \\
\hline F15SF5-H2\% & 0.07 & 0.15 & 0.30 & 0.42 & 0.46 & 0.48 \\
\hline F15SF5-S2\% & 0.07 & 0.14 & 0.31 & 0.46 & 0.48 & 0.50 \\
\hline F15SF5-H3\% & 0.07 & 0.12 & 0.27 & 0.36 & 0.42 & 0.44 \\
\hline F15SF5-S3\% & 0.05 & 0.10 & 0.24 & 0.36 & 0.41 & 0.43 \\
\hline
\end{tabular}

$1 \mathrm{~mm}=0.0394$ inch 


\subsubsection{Influence of Cementitious Materials Combinations}

A typical depth of wear of the plain UHPCs as a function of time is shown in Fig. 6. From Table 5 and Fig. 6, the following observations can be made:

- UHPCs containing fly ash replacing 20 or $30 \%$ Portland cement showed the lowest abrasion resistance after 20 min of testing. The presence of fly ash delayed the strength development of the 28-day-cured UHPCs, and made them comparatively weaker in resisting wear. A comparison between UHPCs F20 and F30 showed a slightly higher depth of wear for up to $12 \mathrm{~min}$ of the testing. Afterwards, UHPC F20 displayed a slightly lower depth of wear, compared to that of the UHPC F30. This finding may be attributed to the higher coefficient of variation displayed by the UHPC F20, as compared to that of the UHPC F30, during the initial period of testing. As testing progressed, this trend reversed itself, resulting in a marginally lower depth of wear for UHPC F20.

- In contrast, the UHPCs made with silica fume displayed the lowest abrasion depth, as silica fume produced more cementitious activities during the 28-day curing period, resulting in the UHPCs with denser and stronger microstructures.

- With increases in time, the rate of abrasion decreased. A major change in the rate of abrasion occurred at about 5 min of testing.

\subsubsection{Influence of Steel Fiber Content and Shape}

The abrasion resistance values for the UHPCs containing 2 and $3 \%$ hooked and straight fibers are documented in Table 5. In general, the introduction of fibers improved the abrasion resistance of the studied UHPCs, and the UHPCs made with $3 \%$ steel fibers produced lower abrasion depths, as compared to the companion UHPCs containing $2 \%$ steel fibers. When $2 \%$ hooked steel fiber was added, after $20 \mathrm{~min}$ of testing, the resistance to abrasion improved by 10, 13, 16,16 , and $9 \%$ for the mixtures C100, SF5, F20, F30, and F15SF5, respectively. With the introduction of 3\% hooked fiber, the corresponding gains in abrasion resistance were $23,22,29,29$, and 20\%, respectively, for the same cementitious materials combinations. In comparison, test samples containing $2 \%$ straight fibers increased abrasion resistance by $18,14,19,19$, and $7 \%$, respectively. The improvements in abrasion of the UHPCs containing 3\% straight steel fibers were nearly identical to those of the companion mixtures made with $3 \%$ hooked fiber.

Overall, hooked fibers increased the abrasion resistance of the studied UHPCs by 15 and $26 \%$ for 2 and 3\% volumetric contents, respectively, when compared with those of the companion plain UHPCs (Fig. 7a). Once straight fibers were used, the resistance to wear increased by 17 and $27 \%$, respectively (Fig. 7b). The reduction in the depth of wear, with increases in fiber content, can be attributed to the anticipated increase in the matrix stiffness of the fibercontaining UHPCs. Depth of wear relationships between plain and fiber-reinforced UHPCs, having coefficient of determination $\left(R^{2}\right)$ values greater than 0.97 at $95 \%$ confidence level, are documented in Fig. 7.

The effect of fiber shape on the depth of wear of the studied UHPCs is presented in Fig. 8. From the parity plot, it can be seen that the shape of fiber had negligible influence on abrasion resistance. Mixtures containing 2 and 3\% straight fibers showed a 4 and $1 \%$ increases in abrasion resistance, respectively, when compared with the companion UHPCs made with hooked fibers. Correlations between straight and hooked fibers, as shown in Fig. 8, stood at the $R^{2}$ values of 0.98 and 0.99 , respectively.

The addition of 2 and $3 \%$ steel fibers to the studied UHPCs resulted in average increases in compressive strengths of 3 and $7 \%$, respectively, when compared to those of the plain UHPCs. In comparison, the improvements in the abrasion resistance of the UHPCs made with 2 and $3 \%$ steel fibers were 15 and $24 \%$, respectively. These observations portray that the addition of steel fibers had more influence on the wear resistance than it did on the compressive strengths of the studied UHPCs.

To determine the relative gain of abrasion depth of the studied UHPCs with respect to the testing duration, abrasion depth ratios at $1,2,5,10$, and $15 \mathrm{~min}$ to the 20-min depth of wear were determined by dividing the abrasion at the time $t$ by the final abrasion depth. The relative gains in abrasion are shown in Table 6 and Fig. 9. The rate of abrasion gain reduced with the testing duration. Moreover, all studied UHPCs attained nearly $85 \%$ of their ultimate depth of wear in the first $10 \mathrm{~min}$ of testing. The relative gains in abrasion remained independent of cementitious materials compositions, steel fiber content ( 2 and $3 \%$ fiber), and steel fiber shape (hooked and straight). The UHPCs without fibers produced average relative gains of 15, 28, 60,86 , and $95 \%$ after $1,2,5,10$, and $15 \mathrm{~min}$, respectively. In comparison, fiber-reinforced UHPCs showed average relative gains of $14,26,58,84$, and $93 \%$ at the same time intervals. The higher initial gains in wear of the studied UHPCs can be attributed to the higher concentrations of abrasive force, due to the smaller ball bearing contact surface, as well as lower surface stiffness of the top mortar paste layer.

\subsubsection{Coefficient of Variation (CV)}

The concrete surfaces in contact with the molds (four surfaces) were tested to ascertain the acceptability of the 

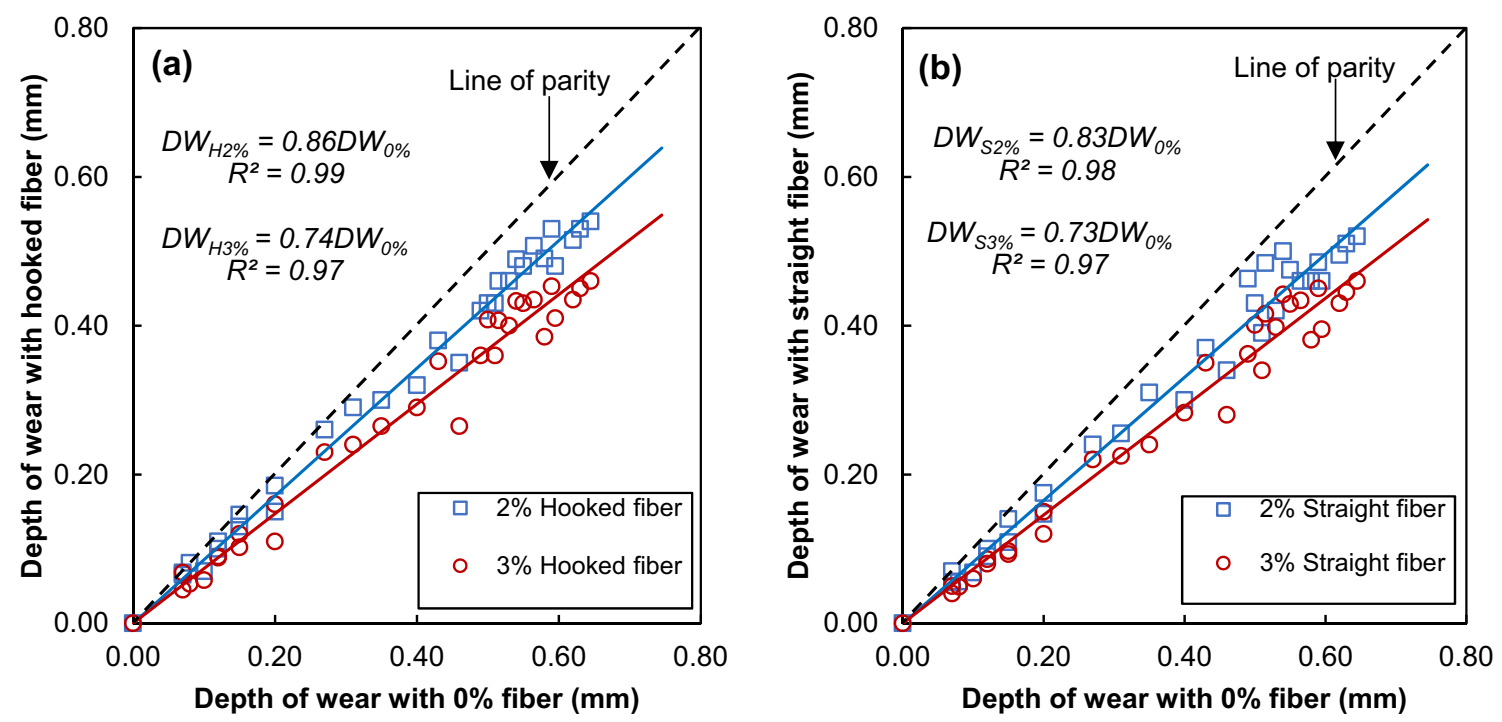

Fig. 7 Effect of steel fiber content on the depth of wear: a effect of hooked fiber, $\mathbf{b}$ effect of straight fiber

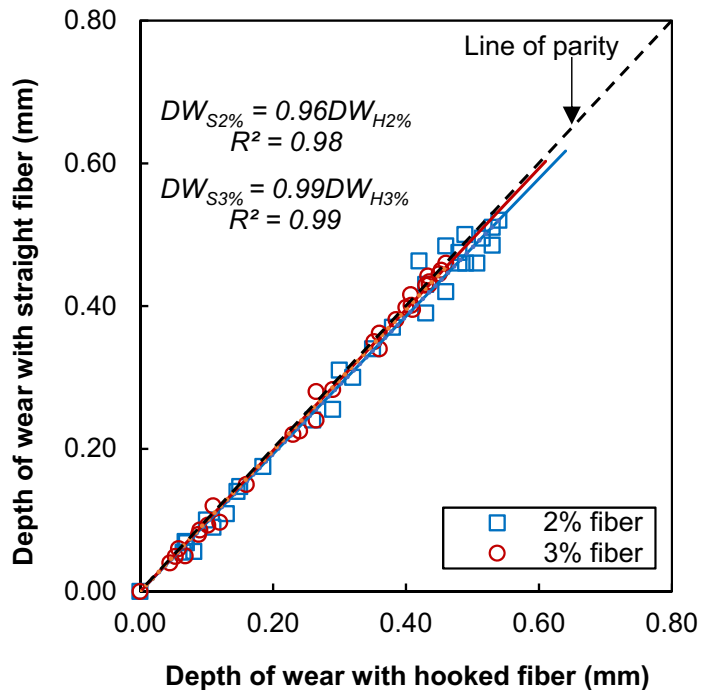

Fig. 8 Effect of steel fiber shape on depth of wear

test results. Following each abrasion test, the abrasion path of the test specimen was carefully examined, and when the abrasion path was not uniform, the result was discarded. Table 7 and Fig. 10 present the coefficients of variation (CV) of the abrasion depth after 1, 2, 5, 10, 15 and 20 min. During the initial testing period, a fully leveled seating of the abrasion apparatus on the concrete surface could not be achieved, resulting in higher CVs. With progress in testing, a more uniform concrete path was developed, and lower than $10 \%$ CVs were observed for most of the studied UHPCs after testing durations of $20 \mathrm{~min}$. On average, the CVs for the plain UHPCs were 27, 18, 15, 12, and 7\% after $1,5,10,15$, and 20 min of testing, respectively. In comparison to the plain UHPCs, the fiber-reinforced mixtures displayed higher CVs at the levels of $36,23,17,12$, and $9 \%$, respectively, for the same time intervals.

\subsubsection{Abrasion Index}

An abrasion index $(A I)$ was also used to examine the resistance to wear of the studied UHPCs. The $A I$ was calculated using the following formula [15]:

$A I=\frac{\sqrt{R}}{P}$

where $A I$ is abrasion index, $R$ is the ball race revolution (in thousands), and $P$ is the depth of abrasion (in $\mathrm{mm}$ or inch).

Based on the results presented in Table 8 and Fig. 11, several observations can be made:

- Due to their strong microstructures, the studied UHPCs produced very high abrasion indices. As a reference, the accepted $A I$ for roadways and industrial settings is 1.20 .

- The UHPCs made with 5\% silica fume, as a replacement of total cementitious materials, showed the highest abrasion indices, whereas UHPCs containing fly ash produced the contrary.

- On average, UHPCs at 20-min testing duration displayed 7 and $15 \%$ higher AIs, as compared to those of the 10- and 15-min testing durations, respectively.

- The addition of steel fibers had a positive impact on the abrasion indices of the studied UHPCs. The inclusion of steel fibers increased $A I$ by $22 \%$ on average, as compared to that of the plain UHPCs. The abrasion indices also improved with increases in fiber content from 2 to $3 \%$. 
Table 6 Relative gain of abrasion depth of UHPC mixtures at 28 days

\begin{tabular}{|c|c|c|c|c|c|c|}
\hline \multirow[t]{2}{*}{ Mixture designation } & \multicolumn{6}{|c|}{ Rate of wear of UHPCs at various testing time } \\
\hline & $1 \mathrm{~min}$ & $2 \mathrm{~min}$ & $5 \min$ & $10 \mathrm{~min}$ & $15 \mathrm{~min}$ & $20 \min$ \\
\hline C100 & 0.20 & 0.34 & 0.68 & 0.90 & 0.96 & 1.00 \\
\hline $\mathrm{C} 100-\mathrm{H} 2 \%$ & 0.19 & 0.35 & 0.60 & 0.87 & 0.96 & 1.00 \\
\hline $\mathrm{C} 100-\mathrm{S} 2 \%$ & 0.21 & 0.36 & 0.62 & 0.87 & 0.95 & 1.00 \\
\hline $\mathrm{C} 100-\mathrm{H} 3 \%$ & 0.20 & 0.35 & 0.64 & 0.88 & 0.96 & 1.00 \\
\hline $\mathrm{C} 100-\mathrm{S} 3 \%$ & 0.19 & 0.33 & 0.63 & 0.88 & 0.96 & 1.00 \\
\hline SF5 & 0.13 & 0.22 & 0.49 & 0.78 & 0.91 & 1.00 \\
\hline SF5-H2\% & 0.14 & 0.23 & 0.54 & 0.79 & 0.90 & 1.00 \\
\hline SF5-S2\% & 0.12 & 0.19 & 0.51 & 0.78 & 0.91 & 1.00 \\
\hline SF5-H3\% & 0.10 & 0.20 & 0.53 & 0.82 & 0.95 & 1.00 \\
\hline SF5-S3\% & 0.09 & 0.19 & 0.51 & 0.82 & 0.93 & 1.00 \\
\hline F20 & 0.16 & 0.31 & 0.71 & 0.90 & 0.96 & 1.00 \\
\hline $\mathrm{F} 20-\mathrm{H} 2 \%$ & 0.13 & 0.28 & 0.65 & 0.91 & 0.95 & 1.00 \\
\hline F20-S2\% & 0.13 & 0.28 & 0.65 & 0.88 & 0.95 & 1.00 \\
\hline F20-H3\% & 0.13 & 0.24 & 0.58 & 0.84 & 0.95 & 1.00 \\
\hline F20-S3\% & 0.13 & 0.26 & 0.61 & 0.83 & 0.93 & 1.00 \\
\hline F30 & 0.13 & 0.24 & 0.49 & 0.81 & 0.94 & 1.00 \\
\hline $\mathrm{F} 30-\mathrm{H} 2 \%$ & 0.15 & 0.25 & 0.55 & 0.81 & 0.91 & 1.00 \\
\hline F30-S2\% & 0.11 & 0.21 & 0.50 & 0.76 & 0.90 & 1.00 \\
\hline F30-H3\% & 0.12 & 0.23 & 0.53 & 0.80 & 0.91 & 1.00 \\
\hline F30-S3\% & 0.11 & 0.21 & 0.51 & 0.76 & 0.89 & 1.00 \\
\hline F15SF5 & 0.13 & 0.28 & 0.65 & 0.91 & 0.95 & 1.00 \\
\hline F15SF5-H2\% & 0.14 & 0.30 & 0.61 & 0.86 & 0.94 & 1.00 \\
\hline F15SF5-S2\% & 0.14 & 0.28 & 0.62 & 0.93 & 0.97 & 1.00 \\
\hline F15SF5-H3\% & 0.16 & 0.28 & 0.61 & 0.83 & 0.94 & 1.00 \\
\hline F15SF5-S3\% & 0.20 & 0.34 & 0.68 & 0.90 & 0.96 & 1.00 \\
\hline
\end{tabular}

\subsection{Relationship Between Compressive Strength, Splitting-Tensile Strength, and Elastic Modulus with Depth of Wear}

The relationship between the depth of wear $(D W)$ and compressive strength $\left(f_{c}^{\prime}\right)$ of the 28-day-cured UHPCs (at a 95\% confidence level) is shown in Fig. 12a and Eq. (2). As can be seen, with increases in compressive strength, the depth of wear of the studied UHPCs decreased. A similar trend was also reported by Pyo et al. [40]. The correlation between the depth of wear and the splitting-tensile strength $\left(f_{t}\right)$ of the studied UHPCs is shown in Fig. 12b and Eq. (3). Pyo et al. [40] developed a correlation between the tensile strength of UHPC with mass loss, and found that the tensile strength of concrete played a positive role in reducing the mass loss after an abrasion test. Figure 12c and Eq. (4) document the relationship between depth of wear and elastic modulus $\left(E_{c}\right)$ of the studied UHPCs.

$D W=9333.6 f_{c}^{\prime}-2.02 \quad R^{2}=0.60$ 
Table 7 Coefficient of variation $(\mathrm{CV})$ for the abrasion test of UHPC mixtures

\begin{tabular}{|c|c|c|c|c|c|c|}
\hline \multirow[t]{2}{*}{ Mixture designation } & \multicolumn{6}{|c|}{$\mathrm{CV}$ for the wear test of UHPCs at various testing time } \\
\hline & $1 \mathrm{~min}$ & $2 \min$ & $5 \mathrm{~min}$ & $10 \mathrm{~min}$ & $15 \mathrm{~min}$ & $20 \mathrm{~min}$ \\
\hline C100 & 36.42 & 34.86 & 29.35 & 19.45 & 18.63 & 8.97 \\
\hline $\mathrm{C} 100-\mathrm{H} 2 \%$ & 42.68 & 36.32 & 31.54 & 20.46 & 22.39 & 10.73 \\
\hline C100-S2\% & 38.03 & 19.31 & 15.25 & 16.24 & 12.70 & 9.01 \\
\hline $\mathrm{C} 100-\mathrm{H} 3 \%$ & 47.59 & 37.54 & 27.23 & 21.59 & 16.54 & 11.61 \\
\hline $\mathrm{C} 100-\mathrm{S} 3 \%$ & 46.37 & 35.20 & 18.07 & 6.40 & 6.94 & 5.93 \\
\hline SF5 & 23.18 & 22.93 & 13.49 & 12.39 & 9.54 & 3.97 \\
\hline SF5-H2\% & 25.63 & 24.82 & 17.32 & 16.30 & 12.61 & 8.56 \\
\hline SF5-S2\% & 38.20 & 43.21 & 16.74 & 15.95 & 9.83 & 5.55 \\
\hline SF5-H3\% & 29.32 & 33.52 & 20.05 & 19.32 & 11.75 & 10.61 \\
\hline SF5-S3\% & 26.84 & 17.81 & 18.00 & 16.87 & 10.04 & 7.59 \\
\hline F20 & 28.39 & 31.20 & 9.97 & 14.58 & 8.94 & 7.52 \\
\hline F20-H2\% & 34.00 & 31.87 & 35.43 & 16.32 & 7.89 & 8.35 \\
\hline F20-S2\% & 19.32 & 21.57 & 18.41 & 10.35 & 6.84 & 8.16 \\
\hline F20-H3\% & 48.21 & 36.04 & 33.21 & 14.86 & 12.73 & 8.83 \\
\hline F20-S3\% & 42.62 & 32.19 & 27.58 & 16.41 & 13.52 & 8.27 \\
\hline F30 & 21.20 & 23.24 & 18.17 & 13.52 & 7.51 & 5.50 \\
\hline F30-H2\% & 31.78 & 25.64 & 26.94 & 19.47 & 16.31 & 12.14 \\
\hline F30-S2\% & 33.42 & 19.63 & 21.42 & 13.54 & 9.62 & 8.17 \\
\hline F30-H3\% & 41.47 & 38.21 & 32.14 & 18.92 & 17.52 & 12.41 \\
\hline F30-S3\% & 45.21 & 36.07 & 21.57 & 20.79 & 12.64 & 11.42 \\
\hline F15SF5 & 27.58 & 26.71 & 18.64 & 17.54 & 13.57 & 9.21 \\
\hline F15SF5-H2\% & 40.11 & 45.37 & 17.58 & 16.75 & 10.32 & 5.83 \\
\hline F15SF5-S2\% & 31.96 & 36.54 & 21.85 & 21.06 & 12.81 & 11.56 \\
\hline F15SF5-H3\% & 28.85 & 32.98 & 19.73 & 19.01 & 11.56 & 10.44 \\
\hline F15SF5-S3\% & 26.17 & 17.36 & 17.55 & 16.45 & 9.79 & 7.40 \\
\hline
\end{tabular}

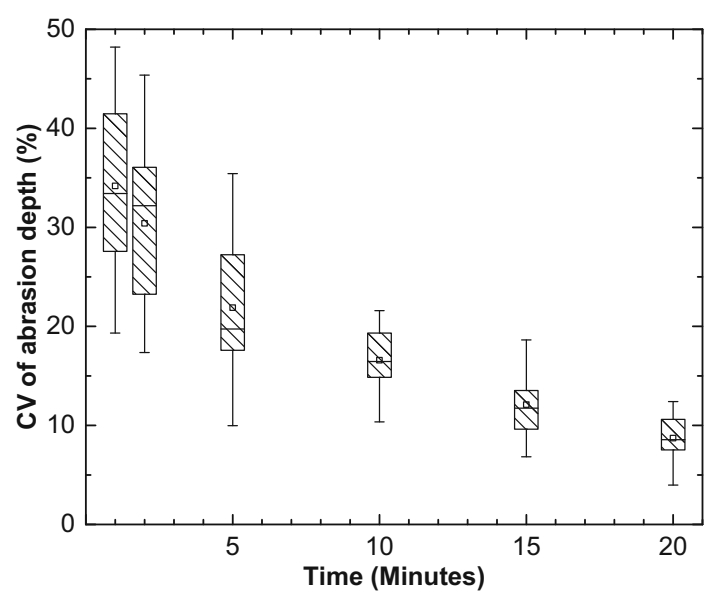

Fig. 10 Coefficients of variation of abrasion depth of the studied UHPCs as a function of time

$$
\begin{aligned}
& D W=4.3 f_{t}^{-0.90} \quad R^{2}=0.93 \\
& D W=314.1 E_{c}^{-1.735} \quad R^{2}=0.60
\end{aligned}
$$

\subsection{Observation of UHPC Surface after Abrasion Test}

The abraded surfaces of the typical UHPCs (with and without fibers) after completion of the tests are shown in Fig. 13. As shown in Fig. 13a, both fine aggregate and pastes were integrally worn away. This was due to the strong bond action between the aggregate and paste. As shown in Fig. 13b, the orientation of steel fibers played a role in resistance to wear. Steel fibers parallel to the contact surface acted jointly with the matrix to increase concrete stiffness and abrasion resistance. Those fibers not parallel to the concrete surface generated shadow zones just below the fibers to protect the underlying matrix against wear.

\subsection{Comparison Between UHPCs and HSCs}

The compressive strength and depth of wear of the studied UHPCs (plain and fiber-reinforced) were compared with those of the two high-strength concretes (HSC1 and HSC2), and the results are presented in Fig. 14. As can be 
Table 8 Abrasion index of UHPCs

\begin{tabular}{lrrrrrr}
\hline Mixture designation & \multicolumn{7}{l}{ Abrasion index of UHPCs at various testing time } & & \\
\cline { 2 - 7 } & 1 min & 2 min & 5 min & 10 min & 15 min & 20 min \\
\hline C100 & 8.3 & 7.1 & 5.6 & 6.0 & 6.9 & 7.6 \\
C100-H2\% & 10.0 & 7.6 & 7.0 & 6.9 & 7.6 & 8.4 \\
C100-S2\% & 10.0 & 8.1 & 7.5 & 7.5 & 8.4 & 9.2 \\
C100-H3\% & 11.1 & 8.8 & 7.7 & 7.9 & 8.9 & 9.9 \\
C100-S3\% & 11.6 & 9.4 & 7.9 & 7.9 & 8.9 & 9.9 \\
SF5 & 14.3 & 11.8 & 8.3 & 7.4 & 7.7 & 8.1 \\
SF5-H2\% & 15.4 & 12.9 & 8.6 & 8.3 & 9.0 & 9.3 \\
SF5-S2\% & 18.2 & 15.7 & 9.3 & 8.5 & 9.0 & 9.4 \\
SF5-H3\% & 22.2 & 16.1 & 9.7 & 9.0 & 9.5 & 10.4 \\
SF5-S3\% & 25.0 & 17.7 & 10.2 & 9.0 & 9.7 & 10.4 \\
F20 & 10.0 & 7.1 & 4.9 & 5.5 & 6.2 & 6.9 \\
F20-H2\% & 14.3 & 9.4 & 6.4 & 6.5 & 7.5 & 8.3 \\
F20-S2\% & 14.7 & 9.6 & 6.6 & 6.9 & 7.8 & 8.6 \\
F20-H3\% & 17.2 & 12.9 & 8.4 & 8.2 & 8.9 & 9.7 \\
F20-S3\% & 16.7 & 11.8 & 8.0 & 8.3 & 9.0 & 9.7 \\
F30 & 12.5 & 9.4 & 7.2 & 6.2 & 6.5 & 7.1 \\
F30-H2\% & 12.3 & 10.9 & 7.7 & 7.4 & 8.1 & 8.4 \\
F30-S2\% & 17.9 & 13.0 & 8.8 & 8.1 & 8.4 & 8.8 \\
F30-H3\% & 18.9 & 13.9 & 9.3 & 8.8 & 9.4 & 9.9 \\
F30-S3\% & 20.4 & 15.2 & 9.9 & 9.3 & 9.8 & 10.0 \\
F15SF5 & 14.3 & 9.4 & 6.4 & 6.5 & 7.5 & 8.3 \\
F15SF5-H2\% & 14.7 & 9.7 & 7.5 & 7.5 & 8.4 & 9.1 \\
F15SF5-S2\% & 14.3 & 10.1 & 7.2 & 6.8 & 8.0 & 8.9 \\
F15SF5-H3\% & 14.7 & 11.8 & 8.4 & 8.8 & 9.5 & 10.3 \\
F15SF5-S3\% & 20.0 & 14.6 & 9.3 & 8.7 & 9.3 & 10.1 \\
\hline & & & & & \\
& & & & & & \\
\end{tabular}

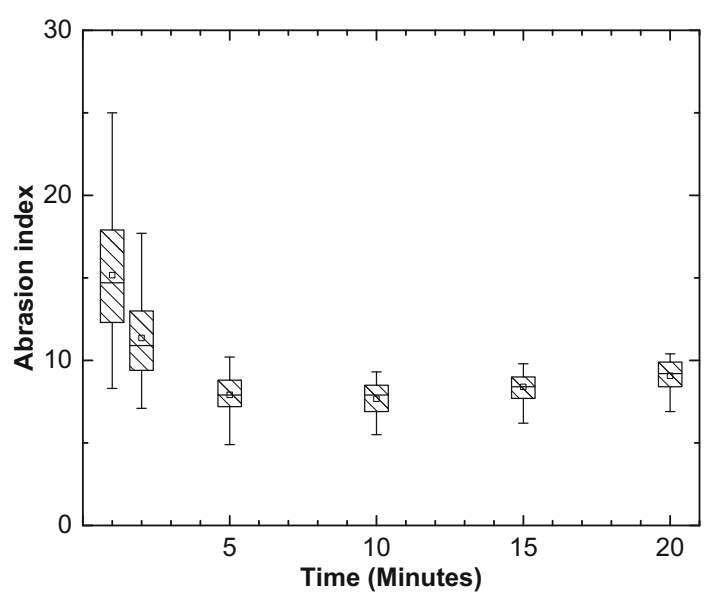

Fig. 11 Abrasion index of the studied UHPCs as a function of time

seen, HSC2 exhibited $11 \%$ improvement in abrasion resistance, over that of $\mathrm{HSC} 1$, while its compressive strength increased by nearly $10 \%$. In comparison to the HSCs, the plain UHPC-C100 displayed an approximately $16 \%$ increase in wear resistance, whereas its compressive strength improved by nearly $30 \%$. The introduction of steel fibers in the UHPC-C100 widened the gap between the two concrete types by a nearly $32 \%$ improvement in wear resistance, whereas their compressive strengths remained nearly unchanged. The significantly higher cementitious material content used in the studied UHPCs, as compared to those of the HSCs, had more influence in improving compressive strength than it did in improving its resistance to wear.

A comparison between the depths of wear and splittingtensile strengths of the studied HSCs and UHPCs is illustrated in Fig. 15. Plain HSC2 displayed a $6 \%$ increase in splitting-tensile strength as compared to that of the HSC1, whereas the abrasion resistance increased by $11 \%$. UHPCC100 produced a $42 \%$ higher splitting-tensile strength compared to those of the HSCs. With the introduction of steel fibers, the improvement in splitting-tensile strength increased to $54 \%$. The aforementioned results indicate that the steel fibers improved splitting-tensile strength and resistance to wear more than they did compressive strength.

While elastic, the moduli of the plain HSCs and UHPCs were nearly identical, the depth of wear decreased by $11 \%$ for plain UHPCs as compared to HSCs (Fig. 5). The 

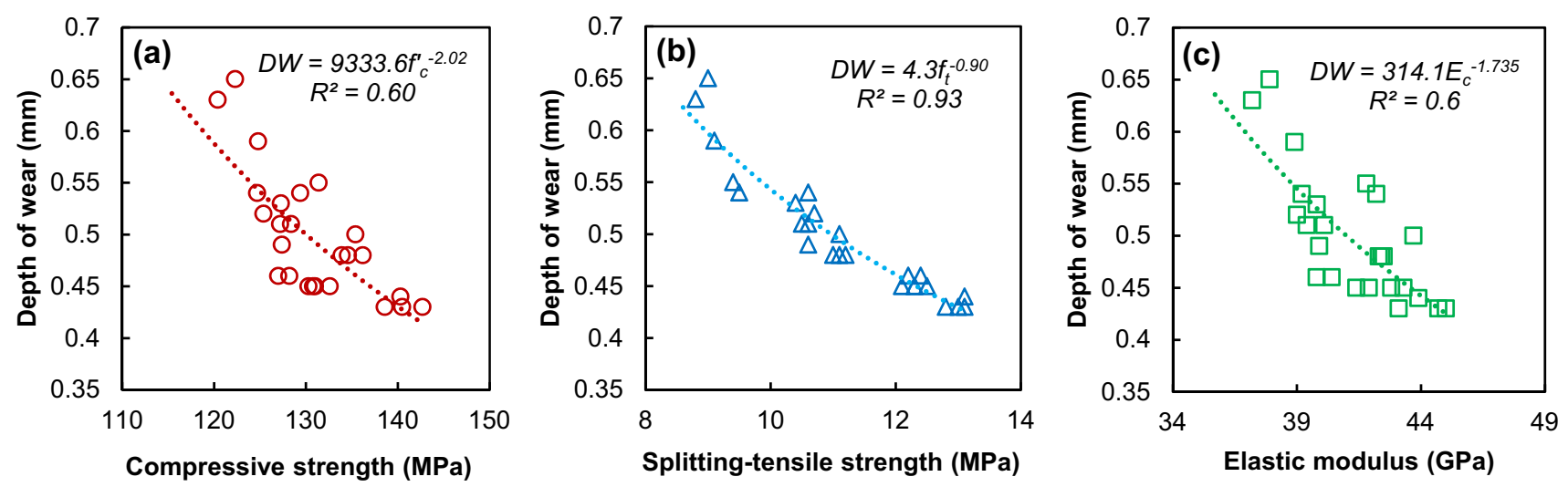

Fig. 12 Correlations between UHPCs' bulk properties and depth of wear: a compressive strength and depth of wear, b splitting-tensile strength and depth of wear, $\mathbf{c}$ elastic modulus and depth of wear

Fig. 13 The abraded surface of typical UHPC after 20 min of testing: a plain UHPC, b steel fiber-reinforced UHPC
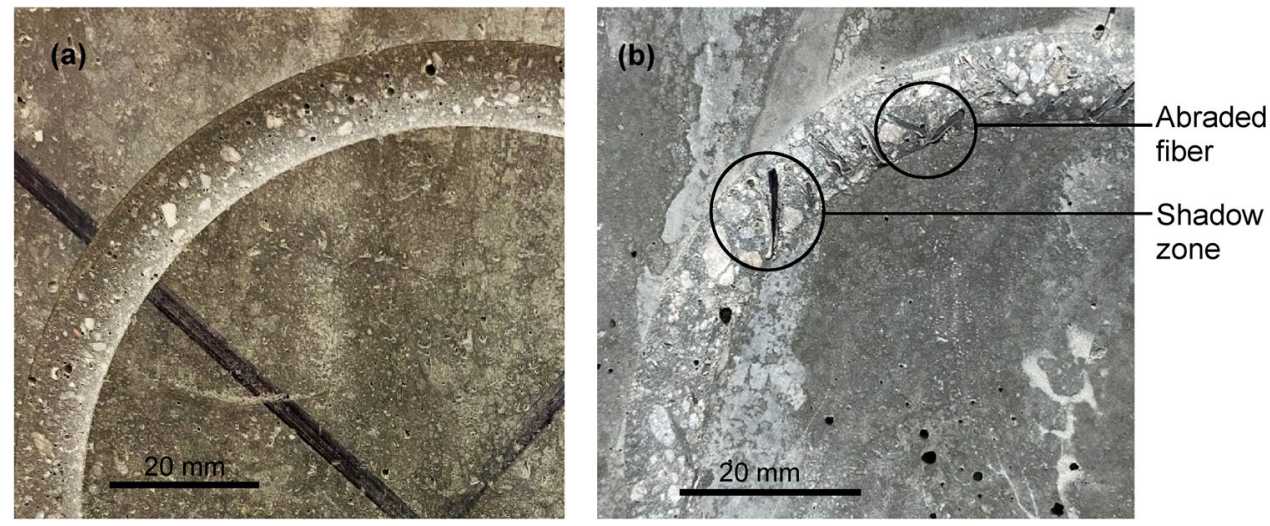

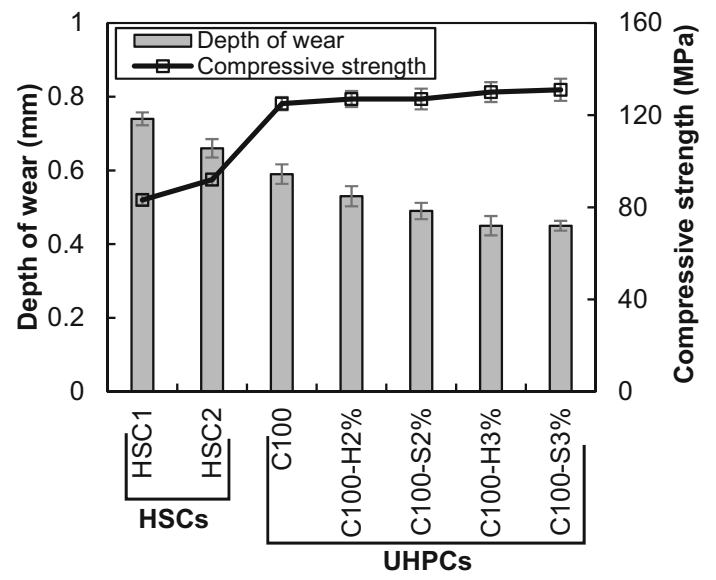

Fig. 14 Comparison between UHPC with HSC in terms of wear and compressive strength

addition of steel fibers slightly improved the elastic moduli of UHPCs (3\% improvement) as compared to the HSCs, whereas the improvement to wear was $32 \%$.

After 20 min of testing, HSC1 and HSC2 showed an AI of 6.0 and 6.8 , respectively. In comparison, the plain

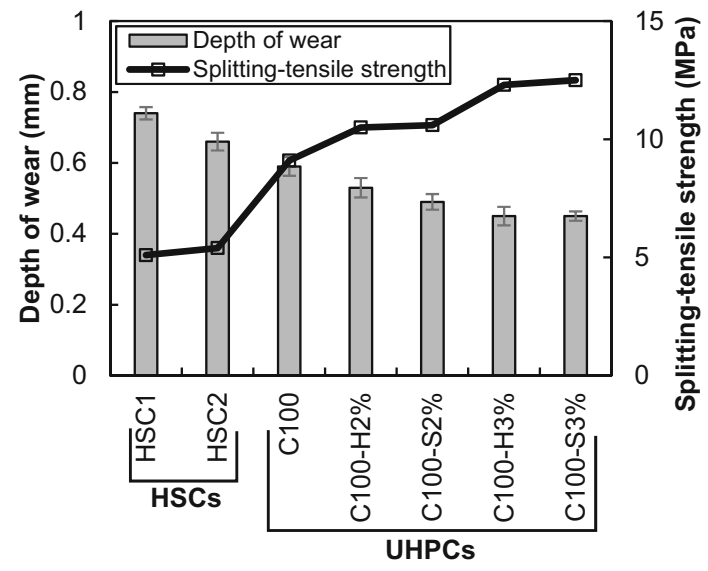

Fig. 15 Comparison between UHPC and HSC in terms of wear and splitting-tensile strength

UHPC (C100) produced an AI of 7.6, an increase of $16 \%$ compared to those of the HSCs. Once steel fibers were incorporated, the fiber-reinforced UHPCs displayed $32 \%$ higher AIs, as compared to those of the studied HSCs. 


\section{Conclusions}

Based on the results of this study, the following conclusions can be drawn:

1. The studied UHPCs displayed excellent compressive, splitting-tensile, and stiffness properties. The variations in cementitious materials combinations had a less positive effect on splitting-tensile resistance and elastic moduli than they had on compressive strength. The low water-to-cementitious materials ratio, very high cementitious materials content, and customized natural aggregate gradation produced a very dense matrix, which resulted in the excellent resistance to wear displayed by the studied UHPCs.

2. Amongst the studied cementitious materials combinations, the 28-day-cured UHPCs containing silica fume showed the highest resistance to wear, whereas the UHPCs containing fly ash produced the contrary.

3. The addition of steel fibers improved the abrasion resistance of the studied UHPCs. The inclusion of steel fibers had more influence in improving the abrasion resistance $(20 \%)$ than it did on the compressive strength $(5 \%)$ of the studied UHPCs. Minimal differences in wear resistance and compressive strength were observed between the straight and hooked steel fibers.

4. Nearly $85 \%$ of the UHPCs' ultimate wear was attained in the first $10 \mathrm{~min}$ of testing.

5. The relative gain in abrasion of the studied UHPCs was independent of cementitious materials compositions or steel fiber content or type.

6. The higher cementitious materials content of the UHPCs, as compared to those of the HSCs, enhanced the compressive strength more than the resistance to wear. In contrast, the increase in cementitious materials contents of the studied HSCs improved the resistance to wear more than the bulk properties.

7. Railway sleepers made with UHPC can produce superior bulk properties and resistance to wear, as compared to the currently used prestressed concrete sleepers.

Acknowledgements Thanks are extended to a number of producers who donated materials. Their names are withheld to avoid any concern of marketing or private interest.

Funding This study was funded by a grant made possible by the University Transportation Center through the US Department of Transportation (Grant No. GR09035).

Conflict of interest The authors declare that they have no conflict of interest.
Open Access This article is licensed under a Creative Commons Attribution 4.0 International License, which permits use, sharing, adaptation, distribution and reproduction in any medium or format, as long as you give appropriate credit to the original author(s) and the source, provide a link to the Creative Commons licence, and indicate if changes were made. The images or other third party material in this article are included in the article's Creative Commons licence, unless indicated otherwise in a credit line to the material. If material is not included in the article's Creative Commons licence and your intended use is not permitted by statutory regulation or exceeds the permitted use, you will need to obtain permission directly from the copyright holder. To view a copy of this licence, visit http://creativecommons. org/licenses/by/4.0/.

\section{References}

1. Railway Technology (2020) At a Glance: Railway Sleeper Materials. https://www.railway-technology.com/features/fea ture92105/. Accessed 25th April 2020

2. Bezgin NÖ (2017) High performance concrete requirements for prefabricated high speed railway sleepers. Constr Build Mater 138:340-351

3. Kaewunruen S, Remennikov AM (2009) Progressive failure of prestressed concrete sleepers under multiple high-intensity impact loads. Eng Struct 31(10):2460-2473

4. Parvez A, Foster SJ (2017) Fatigue of steel-fibre-reinforced concrete prestressed railway sleepers. Eng Struct 141:241-250

5. Janeliukstis R, Clark A, Papaelias M, Kaewunruen S (2019) Flexural cracking-induced acoustic emission peak frequency shift in railway prestressed concrete sleepers. Eng Struct 178:493-505

6. Manalo A, Aravinthan T, Karunasena W, Ticoalu A (2010) A review of alternative materials for replacing existing timber sleepers. Compos Struct 92(3):603-611

7. Zeman, J. C., Edwards, J. R., Barkan, C. P., \& Lange, D. A. (2009, June). Failure mode and effect analysis of concrete ties in North America. In: Proceedings of the 9th International Heavy Haul Conference pp 270-278

8. Ferdous W, Manalo A (2014) Failures of mainline railway sleepers and suggested remedies-review of current practice. Eng Fail Anal 44:17-35

9. Liu TC (1981) Abrasion resistance of concrete. ACI Journal Proceedings 78(5):341-350

10. Dhir RK, Hewlett PC, Chan YN (1991) Near-surface characteristics of concrete: abrasion resistance. Mater Struct 24(2):122. https://doi.org/10.1007/BF02472473

11. Remennikov AM, Kaewunruen S (2014) Experimental load rating of aged railway concrete sleepers. Eng Struct 76:147-162

12. ACI Manual of Concrete Practice Index ACI Concrete Terminology, American Concrete Institute (2015), 38800 Country Club, Dr. Farmington Hills, MI 48331

13. Reiff R, Walker R, Schreiber P, Wilson N, Thompson H (2012) Assessment of Rail Seat Abrasion Patterns and Environment (No. DOT/FRA/ORD-12/07). United States. Federal Railroad Administration

14. Riding KA, Peterman RJ, Guthrie WS, Brueseke M, Mosavi H, Daily K (2019) A study of environmental and track factors that contribute to abrasion damage of concrete ties (No. DOT/FRA/ ORD-19/38). United States. Department of transportation. federal railroad administration. office of research, development, and technology

15. Smith FL (1958) Effect of aggregate quality on resistance of concrete to abrasion. Cement and concrete, American Society for Testing and Materials, Philadelphia. ASTM STP 205:91-105 
16. Li B, Ke G, Zhou M (2011) Influence of manufactured sand characteristics on strength and abrasion resistance of pavement cement concrete. Constr Build Mater 25(10):3849-3853

17. Li H, Zhang MH, Ou JP (2006) Abrasion resistance of concrete containing nano-particles for pavement. Wear 260(11-12):1262-1266

18. Yoshitake I, Ueno S, Ushio Y, Arano H, Fukumoto S (2016) Abrasion and skid resistance of recyclable fly ash concrete pavement made with limestone aggregate. Constr Build Mater 112:440-446

19. Scott BD, Safiuddin M (2015) Abrasion resistance of concrete Design, construction and case study. Concr Res Lett 6(3):136-148

20. Ghafoori N, Sukandar BM (1995) Abrasion resistance of concrete block pavers. ACI Mater J 92(1):25-36

21. Naik TR, Singh SS, Ramme BW (2002) Effect of source of fly ash on abrasion resistance of concrete. J Mater Civ Eng 14(5):417-426

22. Atiş CD (2002) High volume fly ash abrasion resistant concrete. J Mater Civ Eng 14(3):274-277

23. Siddique R (2003) Effect of fine aggregate replacement with Class F fly ash on the abrasion resistance of concrete. Cem Concr Res 33(11):1877-1881

24. Ghafoori N, Diawara H (2007) Strength and wear resistance of sand-replaced silica fume concrete. ACI Mater J 104(2):206

25. Ghafoori N, Najimi M, Aqel MA (2014) Abrasion resistance of self-consolidating concrete. J Mater Civ Eng 26(2):296-303

26. Ghafoori N, Najimi M, Sobhani J (2015) Modelling the abrasion resistance of self-consolidating concrete. Mag Concrete Res 67(17):938-953

27. Ghafoori N, Dutta S (1995) Laboratory investigation of compacted no-fines concrete for paving materials. J Mater Civ Eng 7(3):183-191

28. Sadegzadeh M, Page CL, Kettle RJ (1987) Surface microstructure and abrasion resistance of concrete. Cem Concr Res 17(4):581-590

29. Nanni A (1989) Abrasion resistance of roller compacted concrete. ACI Mater J 86(6):559-565

30. PCA (2020) Ultra-High Performance Concrete. Portland Cement Association (PCA) https://www.cement.org/learn/concrete-tech nology/concrete-design-production/ultra-high-performance-con crete. Accessed $5^{\text {th }}$ February 2020

31. Yang SL, Millard SG, Soutsos MN, Barnett SJ, Le TT (2009) Influence of aggregate and curing regime on the mechanical properties of ultra-high performance fibre reinforced concrete (UHPFRC). Constr Build Mater 23(6):2291-2298

32. Ragalwar K, Heard WF, Williams BA, Ranade R (2020) Significance of the particle size distribution modulus for strainhardening-ultra-high performance concrete (SH-UHPC) matrix design. Constr Build Mater 234:117423

33. Karim R, Najimi M, Shafei B (2019) Assessment of transport properties, volume stability, and frost resistance of non-proprietary ultra-high performance concrete. Constr Build Mater 227:117031
34. Arora A, Almujaddidi A, Kianmofrad F, Mobasher B, Neithalath N (2019) Material design of economical ultra-high performance concrete (UHPC) and evaluation of their properties. Cement Concr Compos 104:103346

35. Yang R, Yu R, Shui Z, Gao X, Xiao X, Zhang X, Wang Y, He Y (2019) Low carbon design of an ultra-high performance concrete (UHPC) incorporating phosphorous slag. J Clean Prod 240:118157

36. Meng W, Valipour M, Khayat KH (2017) Optimization and performance of cost-effective ultra-high performance concrete. Mater Struct. https://doi.org/10.1617/s11527-016-0896-3

37. Zmetra KM, McMullen KF, Zaghi AE, Wille K (2017) Experimental study of UHPC repair for corrosion-damaged steel girder ends. J Bridg Eng 22(8):04017037

38. Graybeal B, Tanesi J (2007) Durability of an ultrahigh-performance concrete. J Mater Civ Eng 19(10):848-854

39. Zhao S, Van Dam E, Lange D, Sun W (2017) Abrasion resistance and nanoscratch behavior of an ultra-high performance concrete. J Mater Civ Eng 29(2):04016212

40. Pyo S, Abate SY, Kim HK (2018) Abrasion resistance of ultrahigh performance concrete incorporating coarser aggregate. Constr Build Mater 165:11-16

41. AREMA Manual for Railway Engineering (2009) American Railway Engineering and Maintenance-of-Way Association (AREMA), Landover, Maryland, vol 1, Ch 30

42. Ngamkhanong C, Li D, Kaewunruen S (2017) Impact capacity reduction in railway prestressed concrete sleepers with surface abrasions. In: IOP conference series: materials science and engineering, vol 245, No 3, p 032048. IOP Publishing. DOI:https://doi.org/10.1088/1757-899X/245/3/032048

43. Ngamkhanong C, Li D, Remennikov AM, Kaewunruen S (2019) Dynamic capacity reduction of railway prestressed concrete sleepers due to surface abrasions considering the effects of strain rate and prestressing losses. Int $\mathrm{J}$ Struct Stab Dyn 19(01):1940001. https://doi.org/10.1142/S0219455419400017

44. Li D, Ngamkhanong C, Kaewunruen S (2017) Influence of surface abrasion on creep and shrinkage of railway prestressed concrete sleepers. In IOP conference series: materials science and engineering, vol 245, No 3, p 032040. IOP Publishing, Bristol

45. You R, Goto K, Ngamkhanong C, Kaewunruen S (2019) Nonlinear finite element analysis for structural capacity of railway prestressed concrete sleepers with rail seat abrasion. Eng Fail Anal 95:47-65

46. Kernes RG, Shurpali AA, Edwards JR, Dersch MS, Lange DA, Barkan CP (2014) Investigation of the mechanics of rail seat deterioration and methods to improve the abrasion resistance of concrete sleeper rail seats. Proc Inst Mech Eng Part F J Rail Rapid Transit 228(6):581-589

47. Kaewunruen S, Ngamkhanong C, Janeliukstis R, You R (2017) Influence of surface abrasions on dynamic behaviours of railway concrete sleepers. In: Proceedings of the 24th international congress on sound and vibration, pp 20-24. London, UK 